\title{
Arctiin blocks hydrogen peroxide-induced senescence and cell death though microRNA expression changes in human dermal papilla cells
}

\author{
Seunghee Bae ${ }^{1}$, Kyung Mi Lim', Hwa Jun Cha', In-Sook An¹, Jeong Pyo Lee², Kwang Sik Lee ${ }^{2}$, Ghang Tai Lee²,
} Kun Kook Lee', Ho Jung Jung ${ }^{3}$, Kyu Joong $\mathrm{Ahn}^{3}$ and Sungkwan $\mathrm{An}^{1 *}$

\begin{abstract}
Background: Accumulating evidence indicates that reactive oxygen species (ROS) are an important etiological factor for the induction of dermal papilla cell senescence and hair loss, which is also known alopecia. Arctiin is an active lignin isolated from Arctium lappa and has anti-inflammation, anti-microbial, and anti-carcinogenic effects. In the present study, we found that arctiin exerts anti-oxidative effects on human hair dermal papilla cells (HHDPCs).

Results: To better understand the mechanism, we analyzed the level of hydrogen peroxide $\left(\mathrm{H}_{2} \mathrm{O}_{2}\right)$-induced cytotoxicity, cell death, ROS production and senescence after arctiin pretreatment of HHDPCs. The results showed that arctiin pretreatment significantly inhibited the $\mathrm{H}_{2} \mathrm{O}_{2}$-induced reduction in cell viability. Moreover, $\mathrm{H}_{2} \mathrm{O}_{2}$-induced sub-G1 phase accumulation and $\mathrm{G} 2$ cell cycle arrest were also downregulated by arctiin pretreatment. Interestingly, the increase in intracellular ROS mediated by $\mathrm{H}_{2} \mathrm{O}_{2}$ was drastically decreased in HHDPCs cultured in the presence of arctiin. This effect was confirmed by senescence associated-beta galactosidase (SA- $\beta$-gal) assay results; we found that arctiin pretreatment impaired $\mathrm{H}_{2} \mathrm{O}_{2}$-induced senescence in HHDPCs. Using microRNA (miRNA) microarray and bioinformatic analysis, we showed that this anti-oxidative effect of arctiin in HHDPCs was related with mitogen-activated protein kinase (MAPK) and Wnt signaling pathways.
\end{abstract}

Conclusions: Taken together, our data suggest that arctiin has a protective effect on ROS-induced cell dysfunction in HHDPCs and may therefore be useful for alopecia prevention and treatment strategies.

Keywords: Dermal papilla cell, Senescence, Cell death, microRNA, Arctiin

\section{Background}

Reactive oxygen species (ROS) are reactive oxygencontaining endogenous byproducts that are produced during normal metabolism and play pivotal roles in maintaining homeostasis [1]. Under stressful environmental conditions (e.g., ionizing radiation, ultraviolet (UV) radiation, drugs, and smoke), the levels of ROS, including hydrogen peroxide $\left(\mathrm{H}_{2} \mathrm{O}_{2}\right)$, are significantly increased [2]. These ROS subsequently activate various signaling molecules, including p53 and mitogen-activated protein kinase (MAPK) to induce cell growth arrest and apoptosis [3,4]. In skin, exogenous ROS can cause cellular damage, impaired collagen

\footnotetext{
* Correspondence: ansfgrc@konkuk.ac.kr

'Korea Institute for Skin and Clinical Sciences, Konkuk University, 120

Neungdong-ro, Gwangjin-gu, Seoul 143-701, Republic of Korea

Full list of author information is available at the end of the article
}

synthesis, and keratinocyte apoptosis, which are mainly observed in aged skin [5]. One group reported that high ROS levels are involved in the etiologies underlying vitiligo skin disease and skin cancer [6]. Furthermore, accumulating evidence supports the hypothesis that oxidative stress caused by $\mathrm{H}_{2} \mathrm{O}_{2}$ is a key factor in the onset and progression of hair loss, which is known as alopecia [7-9].

Alopecia is a hair loss skin disorder that typically causes baldness [10]. It was originally defined as an age-dependent or androgen-dependent mechanism in dermal papilla cells (DPCs) [11]. However, clinical reports have demonstrated that alopecia does not occur in an androgen-dependent manner; there are also androgen-independent mechanisms, including chemotherapy-dependent and stress-dependent effects $[9,12,13]$. A growing number of studies have shown that the levels of apoptosis and senescence are 
significantly increased in balding DPCs as compared with non-balding DPCs $[7,14]$. Interestingly, ROS has been known as an important inducer of the androgendependent and -independent alopecia [9]. The dermal papillae of balding scalps showed higher levels of ROS compared with non-balding scalp $[15,16]$. Moreover, increased ROS levels were associated with decreased DPC motility [7]. In addition, DPCs from balding scalp also exhibited higher levels of cell senescence [7]. More recent studies also demonstrated that cisplatin-induced alopecia is mediated by ROS production and ROS-mediated apoptosis in DPCs [17]. These finding have led to the hypothesis that ROS may be an important target when designing therapeutic strategies to prevent or treat alopecia.

Arctiin is a lignin chemical reagent isolated from Arctium lappa. This chemical reagent has been known to exert anti-inflammatory, anti-proliferative, and antimicrobial effects [18-21]. We recently reported that arctiin has a protective effect against UVB radiation in skin cells, including dermal fibroblasts and keratinocytes [22,23]. We subsequently observed that the arctiin-mediated antiphotoaging effect is functionally related with microRNA (miRNA)-mediated signaling pathways [22,23]. However, it is unknown whether arctiin exerts anti-oxidative effects and what biological effects arctiin has on human follicle cells. In present study, we studied the biological events of human hair dermal papilla cells (HHDPCs) in the presence of arctiin and/or $\mathrm{H}_{2} \mathrm{O}_{2}$ and performed cell-based assays to determine whether $\mathrm{H}_{2} \mathrm{O}_{2}$-induced cell dysfunction could be inhibited by arctiin treatment. We also investigated the role of miRNA-mediated mechanisms in using microarrays and bioinformatic analysis.

\section{Results}

Arctiin inhibits $\mathrm{H}_{2} \mathrm{O}_{2}$-mediated cell proliferation loss in a dose-dependent manner in HHDPCs

Before we analyzed the inhibitory effect of arctiin against $\mathrm{H}_{2} \mathrm{O}_{2}$-induced cell dysfunction, we preferentially sought to evaluate the effect of arctiin on HHDPC growth. First, HHDPCs were exposed to different concentrations of arctiin for $24 \mathrm{~h}$, and cell viability was analyzed with WST-1 assays. As shown in Figure 1A, 10, 20, and $30 \mu \mathrm{M}$ arctiin significantly increased cell viability by $38.89 \pm 3.99 \%$, $42.48 \pm 13.69 \%$, and $48.96 \pm 6.07 \%$ compared with dimethyl sulfoxide (DMSO)-treated control cells. However, exposure to larger doses of arctiin $(\geq 40 \mu \mathrm{M})$ did not increase cell viability beyond that observed in cells treated with $10 \mu \mathrm{M}$ arctiin, and $60 \mu \mathrm{M}$ arctiin induced HHDPC cytotoxicity. Therefore, we concluded that an arctiin dose of 10 to $30 \mu \mathrm{M}$ arctiin has maximum growthpromoting effect on HHDPCs, and those doses were used in further experiments.

Next, we investigated the inhibitory effect of arctiin on $\mathrm{H}_{2} \mathrm{O}_{2}$-induced cell dysfunction. We first performed WST-1 assays to analyze the inhibitory effect of $\mathrm{H}_{2} \mathrm{O}_{2}$ on HHDPC viability. Cells were pretreated with 0 to $30 \mu \mathrm{M}$ arctiin for $8 \mathrm{~h}$ and then stimulated with $750 \mu \mathrm{M} \mathrm{H}_{2} \mathrm{O}_{2}$. Cell viability was analyzed after $24 \mathrm{~h}$. As expected, arctiin pretreatment attenuated the $\mathrm{H}_{2} \mathrm{O}_{2}$-induced decrease in cell viability in a dose-dependent manner (Figure $1 \mathrm{~B}$ ). DMSO and $\mathrm{H}_{2} \mathrm{O}_{2}$ treated cells showed a $38.15 \pm 3.52 \%$ reduction in cell viability compared with untreated cells; however, 10, 20, and $30 \mu \mathrm{M}$ arctiin-pretreated and $\mathrm{H}_{2} \mathrm{O}_{2}$-posttreated cells showed only $13.95 \pm 3.34 \%, 7.49 \pm 4.40 \%$, and $7.54 \pm 2.68 \%$ reductions compared with untreated cells, respectively. These results indicate that arctiin attenuates $\mathrm{H}_{2} \mathrm{O}_{2}$-mediated cytotoxicity in HHDPCs.

\section{Arctiin inhibits $\mathrm{H}_{2} \mathrm{O}_{2}$-mediated cell death and cell cycle arrest in HHDPCs}

To confirm the result shown in Figure 1B, we performed cell cycle analyses using PI staining and flow cytometry. HHDPCs were treated with arctiin and $\mathrm{H}_{2} \mathrm{O}_{2}$ under the same conditions used for Figure $1 \mathrm{~B}$, and then cells were stained with PI solution to analyze cell cycle patterns. As shown in Figure 2A, arctiin and $\mathrm{H}_{2} \mathrm{O}_{2}$ treatment altered
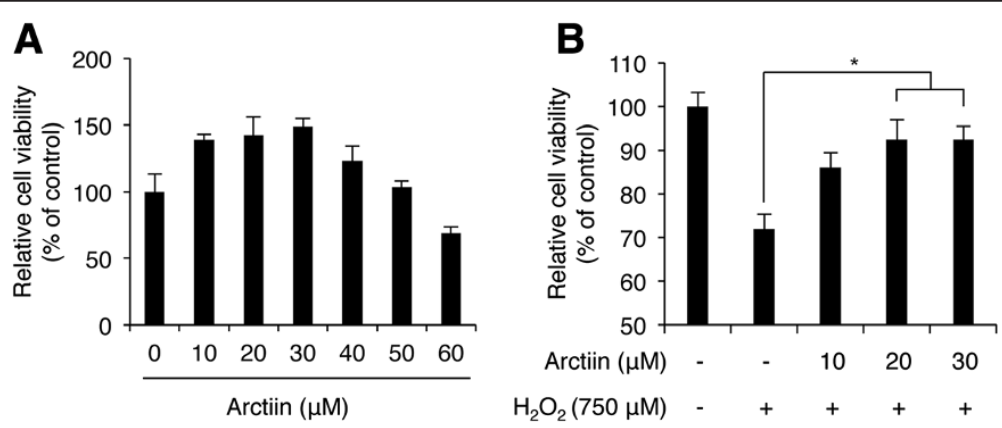

Figure $1 \mathrm{H}_{2} \mathrm{O}_{2}$-mediated loss of HDPPC viability was rescued by arctiin treatment. (A) WST-1 cytotoxicity assays of HHDPCS treated with various doses of arctiin. Each bar represents the mean \pm SD from three independent experiments. (B) Arctiin dose-dependently inhibited $\mathrm{H}_{2} \mathrm{O}_{2}$-induced cytotoxicity as measured with WST-1 assays. The graph represents the mean \pm S.D. of relative cell viability from triplicate experiments. ${ }^{*} p<0.05$ compared with $\mathrm{H}_{2} \mathrm{O}_{2}$-treated HHDPCs. 

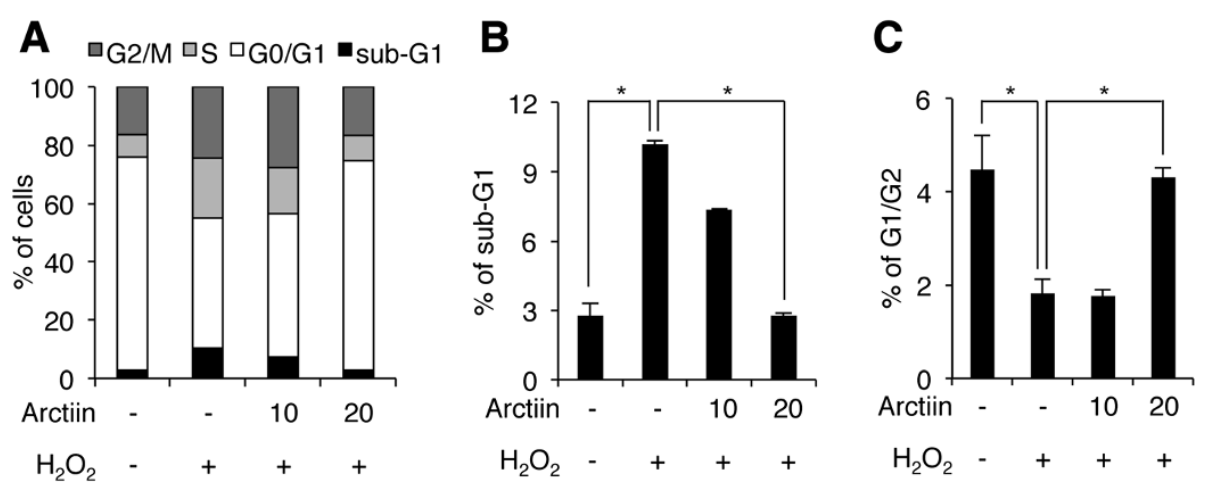

Figure $2 \mathrm{H}_{2} \mathrm{O}_{2}$-induced $\mathrm{G} 2$ arrest and cell death were rescued by arctiin. (A) HHDPCs were treated with DMSO or arctiin prior to $\mathrm{H}_{2} \mathrm{O}_{2}$ exposure, and cell cycle status was assessed flow cytometry. (B and $\mathbf{C}$ ) The graphs represent the mean values of cell populations from three independent experiments (sub-G1 and G1/G2, respectively). ${ }^{*} p<0.05$ compared with control or $\mathrm{H}_{2} \mathrm{O}_{2}$-treated HHDPCs.

the cell cycle distribution of HHDPCs. Notably, $\mathrm{H}_{2} \mathrm{O}_{2}$ only treatment led to accumulation of $7.45 \%$ in sub-G1, $12.84 \%$ in $\mathrm{S}$ phase and $7.45 \%$ in $\mathrm{G} 2 / \mathrm{M}$ phase, with a corresponding decrease in the percentage of G0/G1 phase cells as compared with untreated control cells (Figure 2A). We also found that those accumulations in sub-G1, S, and G2/M phases in $\mathrm{H}_{2} \mathrm{O}_{2}$-treated cells were significantly decreased by arctiin pretreatment in a dosedependent manner. Pretreatment with 10 and $20 \mu \mathrm{M}$ arctiin led to reductions of $2.82 \%$ and $7.43 \%$ in sub-G1 phase cells as compared with $\mathrm{H}_{2} \mathrm{O}_{2}$-treated cells, respectively, indicating that arctiin inhibited $\mathrm{H}_{2} \mathrm{O}_{2}$-mediated sub-G1 accumulation, which is indicative of dead cells (Figure 2B). Also, the proportion of G2/G1 cells was increased by $\mathrm{H}_{2} \mathrm{O}_{2}$ treatment as compared with untreated control cells, indicating that $\mathrm{H}_{2} \mathrm{O}_{2}$ induced $\mathrm{G} 2$ arrest in HHDPCs (Figure 2C). However, the proportion of G2 arrest cells was significantly decreased by arctiin pretreatment (Figure 2C). Overall, these results suggest that arctiin blocks $\mathrm{H}_{2} \mathrm{O}_{2}$-mediated cell death and $\mathrm{G} 2$ arrest in HHDPCs.

Arctiin inhibits $\mathrm{H}_{2} \mathrm{O}_{2}$-mediated ROS generation in HHDPCs ROS generation mediated by $\mathrm{H}_{2} \mathrm{O}_{2}$ is characterized by increases in cell death and cell cycle arrest in several cell lines [1]. To determine whether arctiin pretreatment inhibits $\mathrm{H}_{2} \mathrm{O}_{2}$-mediated ROS generation, we performed DCF-DA analyses to assess intracellular ROS production in HHDPCs. As shown in Figure 3A, arctiin did not alter intracellular ROS levels in untreated control cells, but it significantly abolished the $\mathrm{H}_{2} \mathrm{O}_{2}$-induced increase in intracellular ROS generation. Cells treated with $750 \mu \mathrm{M}$ $\mathrm{H}_{2} \mathrm{O}_{2}$ showed a $45.77 \%$ accumulation of $\mathrm{M}$ phase (DCFpositive) cells as compared with untreated control cells (Figure 3B). However, pretreatment with $20 \mu \mathrm{M}$ arctiin, led to reduction of $29.77 \%$ of cells in the $\mathrm{M}$ phase as compared with $\mathrm{H}_{2} \mathrm{O}_{2}$-treated cells (Figure $3 \mathrm{~B}$ ). These results suggest that $\mathrm{H}_{2} \mathrm{O}_{2}$-mediated ROS production in HHDPCs is inhibited by arctiin.

Arctiin inhibits $\mathrm{H}_{2} \mathrm{O}_{2}$-mediated senescence in HHDPCs Cell cycle arrest in the G2 phase and ROS generation are functionally related with cellular senescence $[24,25]$. Therefore, we next determined whether G2 cell cycle arrest and ROS generation contribute to senescence and whether arctiin pretreatment can block $\mathrm{H}_{2} \mathrm{O}_{2}$-mediated senescence in HHDPCs. Using SA- $\beta$-galactosidase (SA- $\beta$ gal) assays, we evaluated cellular senescence by counting the SA- $\beta$-gal-positive blue-stained senescent cells after arctiin and/or $\mathrm{H}_{2} \mathrm{O}_{2}$ treatment under the same experimental conditions shown in Figure $3 \mathrm{~A} . \mathrm{H}_{2} \mathrm{O}_{2}$ treatment increased the percentage of senescent cells by $24.89 \%$ compared with untreated control cells, however, $20 \mu \mathrm{M}$ arctiin pretreatment the percentage of senescent cells by $10.89 \%$ compared with $\mathrm{H}_{2} \mathrm{O}_{2}$-treated cells (Figure 4). These results indicate that arctiin negatively regulates $\mathrm{H}_{2} \mathrm{O}_{2}$-mediated senescence in HHDPCs.

Arctiin alters $\mathrm{H}_{2} \mathrm{O}_{2}$-mediated changes in miRNA expression miRNAs are important small non-coding RNA molecules, and exerts their biological functions by posttranscriptionally regulating those of their target genes [26,27]. Numerous studies have demonstrated that miRNAs regulate 4 major biological functions, such as development, proliferation, differentiation and apoptosis [28,29]. Furthermore, accumulating results have shown that altered miRNA expression profiles are involved in UVB- or $\mathrm{H}_{2} \mathrm{O}_{2}$ - protective effects and even androgenetic alopecia in human skin cells [23,30-32]. Therefore, we next sought to understand the putative molecular mechanism underlying the protective effect of arctiin against $\mathrm{H}_{2} \mathrm{O}_{2}$ in HHDPCs by analyzing miRNA expression changes. We performed miRNA microarrays and identified 30 miRNAs that were differentially expressed following arctiin pretreatment and $\mathrm{H}_{2} \mathrm{O}_{2}$ 

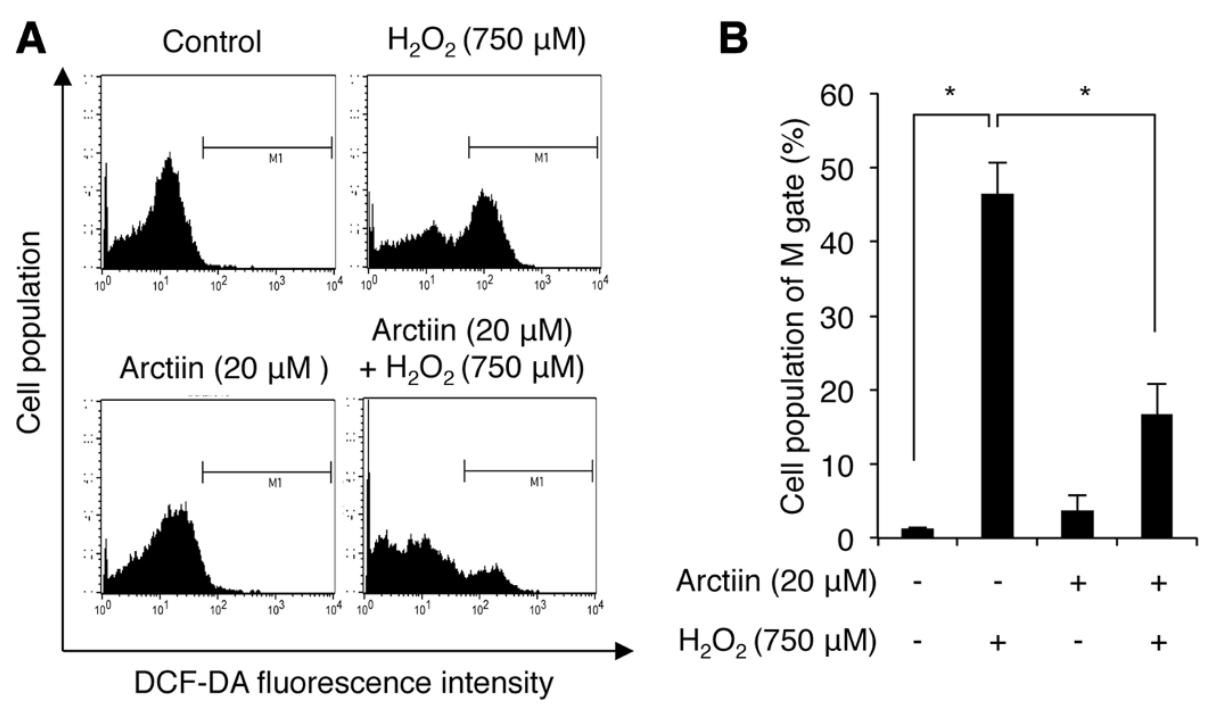

Figure 3 Analysis of intracellular ROS levels with DCF-DA assays. (A) HHDPCs were pre-treated with DMSO or arctiin (20 $\mu \mathrm{M})$ followed by $\mathrm{H}_{2} \mathrm{O}_{2}(750 \mu \mathrm{M})$ prior to flow cytometry. (B) The graph indicates the mean value of M1-phase (DCF-DA-stained) cells from three independent experiments. ${ }^{*} p<0.05$ compared with $\mathrm{H}_{2} \mathrm{O}_{2}$-treated HHDPCs.

exposure as compared with $\mathrm{H}_{2} \mathrm{O}_{2}$-treated cells. Eighteen and 12 miRNAs were upregulated and downregulated more than 2.0-fold, respectively (Table 1 ). The most dysregulated miRNAs were miR-602 (5.74-fold increase) and miR-1290 (5.80-fold decrease). These findings indicate

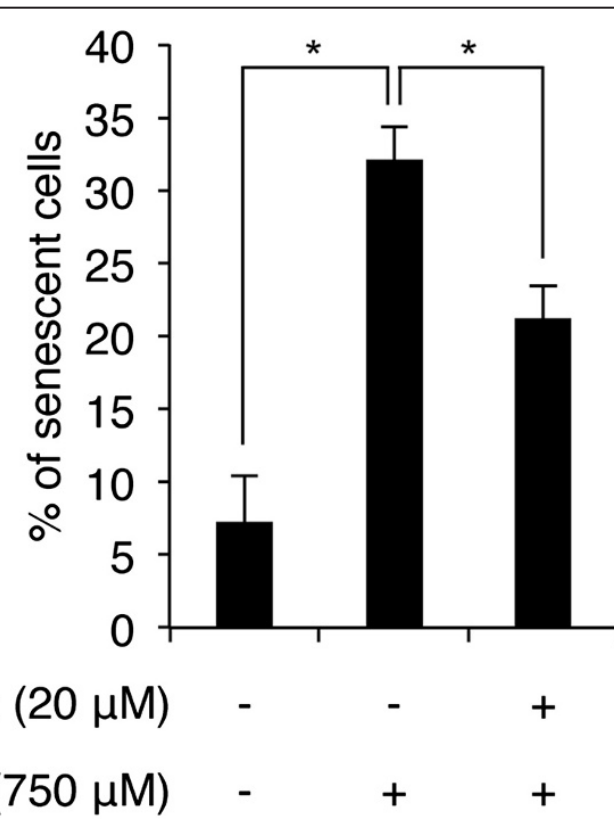

Figure 4 Effect of arctiin on $\mathrm{H}_{2} \mathrm{O}_{2}$-induced senescence as measured by SA- $\beta$-gal assays. HHDPCs were pre-treated with DMSO or arctiin $(20 \mu \mathrm{M})$ followed by $\mathrm{H}_{2} \mathrm{O}_{2}$. The graph indicates the mean value of senescent (SA- $\beta$-gal stained) cells from three independent experiments. ${ }^{*} p<0.05$ compared with $\mathrm{H}_{2} \mathrm{O}_{2}$-treated HHDPCs. that arctiin regulates the expression levels of specific miRNAs in HHDPCs.

To investigate the cellular effect of the altered miRNAs on HHDPCs, we selected the altered specific miRNAs and gathered the list of putative target mRNAs of the miRNAs using a target prediction tool (MicroCosm Targets ver. 5), and then determined the biological functions associated with the target genes by Gene Ontology (GO) analysis using AmiGO bioinformatic tools. Our data show that arctiin has a protective effect against $\mathrm{H}_{2} \mathrm{O}_{2}$ induced cellular senescence and apoptosis in dermal papilla cells; therefore, we analyze GO of the target genes and categorize them into cellular processes including aging, skin development, apoptosis and cell proliferation. As shown in Tables 2 and 3, the altered miRNAs were functionally related in the four biological categories. Mir-602 was the most upregulated miRNA and has many targets including EDN1 and SOD2 (aging); APC (skin development); ERBB4, PPARG, and TP53BP2 (apoptosis); and STAT3, CDK9, and ID4 (cell proliferation). Mir-1290 was the most downregulated miRNA and targets SLC1A2 (aging), APC and COL8A1 (skin development), NOTCH1 and BMI1 (apoptosis), and ROBO1, CDC27 (cell proliferation).

Previous studies have indicated that arctiin-mediated alterations in miRNAs may be involved in regulated the four cellular mechanisms mentioned above. Also, as a matter of fact, the GO term contains bi-directional processes for each term. The term of 'apoptosis' includes both anti-apoptotic and pro-apoptotic processes. Therefore, $\mathrm{GO}$ analysis is not sufficient for understanding the biological functions of altered miRNAs in our study. To improve the accuracy of the biological meaning of the 
Table 1 Significantly altered miRNAs (>2-fold change) following arctiin treatment of $\mathrm{H}_{2} \mathrm{O}_{2}$-exposed HHDPCs

\begin{tabular}{|c|c|c|c|c|c|c|c|}
\hline miRNA & $\begin{array}{c}\text { Change relative } \\
\text { to controls }\end{array}$ & $\begin{array}{c}\text { Direction of } \\
\text { regulation }\end{array}$ & Chromosome & miRNA & $\begin{array}{c}\text { Change relative } \\
\text { to controls }\end{array}$ & $\begin{array}{c}\text { Direction of } \\
\text { regulation }\end{array}$ & Chromosome \\
\hline hsa-miR-1181 & 2.13 & Up & 19 & hsa-miR-874 & 2.97 & Up & 5 \\
\hline hsa-miR-125a-5p & 5.04 & Up & 19 & hsa-miR-890 & 2.83 & Up & $x$ \\
\hline hsa-miR-21-3p & 2.82 & Up & 17 & hsa-miR-939 & 2.59 & Up & 8 \\
\hline hsa-miR-29b-1-5p & 3.12 & Up & 7 & hsa-miR-1290 & -7.56 & Down & 1 \\
\hline hsa-miR-3663-3p & 2.19 & Up & 10 & hsa-miR-1915-3p & -2.63 & Down & 10 \\
\hline hsa-miR-3127-5p & 2.01 & Up & 2 & hsa-miR-2861 & -3.31 & Down & 9 \\
\hline hsa-miR-3663-3p & 2.03 & Up & 10 & hsa-miR-3665 & -2.37 & Down & 13 \\
\hline hsa-miR-371a-5p & 3.14 & Up & 19 & hsa-miR-4257 & -3.62 & Down & 1 \\
\hline hsa-miR-4327 & 2.95 & Up & 21 & hsa-miR-452-5p & -2.54 & Down & $x$ \\
\hline hsa-miR-584-5p & 2.31 & Up & 5 & hsa-miR-513a-5p & -3.15 & Down & $x$ \\
\hline hsa-miR-602 & 5.74 & Up & 9 & hsa-miR-572 & -5.80 & Down & 4 \\
\hline hsa-miR-629-3p & 2.71 & Up & 15 & hsa-miR-629-3p & -3.03 & Down & 15 \\
\hline hsa-miR-642b-3p & 2.10 & Up & 19 & hsa-miR-765 & -7.18 & Down & 1 \\
\hline hsa-miR-651 & 3.91 & Up & $x$ & hsa-miR-875-5p & -3.91 & Down & 8 \\
\hline hsa-miR-762 & 2.84 & Up & 16 & hsa-miR-940 & -2.31 & Down & 16 \\
\hline
\end{tabular}

target genes, the targets were analyzed using the Kyoto Encyclopedia of Genes and Genomes (KEGG) pathwaybased enrichment analysis program in the bioinformatic database DAVID. As shown in Tables 4 and 5, the altered miRNAs may be involved in regulating pathways involved in cancer, cell cycle, and Wnt and MAPK signaling, among others. For example, miR-602 is putatively involved in regulating MAPK and insulin signaling pathways; however, miR-1290 is involved in cancer, focal adhesion, and insulin signaling pathways. Overall, the results indicate that the protective effect of arctiin against $\mathrm{H}_{2} \mathrm{O}_{2}$-induced alterations in HHDPCs may be regulated by arctiin-specific miRNAs and pathways that are possibly affected by miRNAs.

\section{Discussion}

The identification of novel anti-oxidant chemo-reagents is required to effectively treat or prevent alopecia due to androgen dysregulation or oxidative stress. Here, we used cell-based approaches, to demonstrate the potent antioxidant activity of the lignin derivative arctiin. Interestingly, pretreatment with arctiin drastically inhibited $\mathrm{H}_{2} \mathrm{O}_{2}{ }^{-}$ induced decreases in viability in HHDPCs. Flow cytometry demonstrated that arctiin pretreatment also increased HHDPC resistance against cell death and G2 cell cycle arrest mediated by $\mathrm{H}_{2} \mathrm{O}_{2}$. Furthermore, those effects of arctiin were related to its anti-oxidative effect. Upregulation of intracellular ROS levels, which was mediated by $\mathrm{H}_{2} \mathrm{O}_{2}$, was dramatically inhibited following arctiin pretreatment. Recent reports have demonstrated that the loss of proliferative capacity in balding dermal papilla cells is associated with expression changes SA- $\beta$-gal and markers of oxidative stress [7]. We also found that arctiin inhibited $\mathrm{H}_{2} \mathrm{O}_{2}$-mediated upregulation of SA- $\beta$-gal activity in HHDPCs. These findings suggest that arctiin is a novel potent therapeutic agent for oxidative stress-induced cell dysfunction in HHDPCs.

Using miRNA microarrays, we identified 30 miRNAs that may have important roles in the arctiin-mediated protective effect against $\mathrm{H}_{2} \mathrm{O}_{2}$ in HHDPCs. Although further experiments are needed to validate miRNA expression levels to confirm the microarray data, we focused on the biological meaning of the altered miRNAs in our study because the cellular functions of miRNA are dependent on their target mRNAs. Therefore, we used several bioinformatic tools to understand the biological meaning of the altered miRNAs. Our bioinformatical analysis showed that the miRNAs altered in response to arctiin pretreatment before $\mathrm{H}_{2} \mathrm{O}_{2}$ stimulation are commonly involved in MAPK and Wnt signaling pathways. TAK1/MAP3K7 is a member of the MAP3K family, and it has been reported that impaired hair follicle morphogenesis and hair loss are mediated by TAK1/MAP3K7 deletion in mice [33]. Also, TAK1/MAP3K7 deficiency upregulates ROS levels, resulting in skin keratinocyte cell death [34]. Extracellular signal-regulated kinase (ERK), a member of the MAPK family, plays an important role in HHDPC proliferation. ERK signaling is activated by minoxidil, which is a widely used drug for treating androgenetic alopecia, and ERK inhibition blocks the anti-alopecia effect of the minoxidil [35]. In addition, our bioinformatic results showed that MAPK signaling was the most commonly targeted pathway for the downregulated miRNAs mediated by arctiin in HHDPCs (Table 5). This result indicates that MAPK 
Table 2 Predicted targets of miRNAs upregulated by arctiin in $\mathrm{H}_{2} \mathrm{O}_{2}$-treated HHDPCs

\begin{tabular}{|c|c|c|c|c|}
\hline \multirow[b]{2}{*}{ miRNA } & \multicolumn{4}{|c|}{ Target genes and functions } \\
\hline & Aging & $\begin{array}{l}\text { Skin } \\
\text { development }\end{array}$ & Apoptosis & Cell proliferation \\
\hline hsa-miR-1181 & - & - & - & - \\
\hline hsa-miR-125a-5p & $\begin{array}{l}\text { EPO, EDN1, BCL2, } \\
\text { BAK1, CASP2, } \\
\text { PTH1R }\end{array}$ & COL4A3 & $\begin{array}{l}\text { ITCH, COL4A3, HIPK2, RAF1, EPO, EDN1, } \\
\text { BCL2, MAP2K7, MAP3K1, ARHGEF3, } \\
\text { TRAF6, CASP2, BAK1, IRF1, APPL1, ETS1, } \\
\text { BMF, MCL1, BCL2L2, BAG4, HK2, FOXQ1, } \\
\text { CREB1, E2F2, TP73, USP7, MAPK7, FGFR2, } \\
\text { BRCA1, MAP3K11, REST, DICER1, } \\
\text { ARHGEF2, MAP3K10, SORT1, BNIP2, } \\
\text { DDX5, CSNK2A1, MKNK2 }\end{array}$ & $\begin{array}{l}\text { BRCA1, MAP3K11, ETS1, LIF, SOX11, } \\
\text { CD34, NCOR2, BAP1, IRF1, APPL1, REST, } \\
\text { DICER1, EPO, EDN1, BCL2, BAK1, } \\
\text { ARHGEF2, FGFR2, ITCH, ABCB1, COL4A3, } \\
\text { KIF15, HIPK2, RAF1, EIF5A2, CARM1 }\end{array}$ \\
\hline hsa-miR-21-3p & CDK6 & - & $\begin{array}{l}\text { MAP2K4, MAP3K1, BCL2L11, ROBO2, } \\
\text { RNF41, BAG4, CUL3, FOXO3, SMAD3, } \\
\text { AMIGO2, KDM28, DAB2IP, TRIM32, SOX4, } \\
\text { CCAR1, SLC11A2, DSG1 }\end{array}$ & $\begin{array}{l}\text { CDK6, KDM28, CUL3, SOX4, SMAD3, } \\
\text { NR6A1, FTO, CD274, DAB2IP, TRIM32, } \\
\text { FOXO3, PBRM1 }\end{array}$ \\
\hline hsa-miR-29b-1-5p & NR3C1, SIRT1 & - & $\begin{array}{l}\text { NR3C1, SIRT1, REST, PTK2, SOS2, NUAK2, } \\
\text { PSMD7 }\end{array}$ & $\begin{array}{l}\text { NR3C1, SIRT1, REST, PTK2, FGF18, INSR, } \\
\text { PBRM1 }\end{array}$ \\
\hline hsa-miR-3663-3p & $\begin{array}{l}\text { FAS, CASP2, } \\
\text { CDKN1A, PTH1R }\end{array}$ & $\begin{array}{l}\text { ADAMTS2, BCL11B, } \\
\text { COL3A1, COL1A1 }\end{array}$ & $\begin{array}{l}\text { CDKN1A, BCL11B, PPP2R1B, TGFB2, } \\
\text { DDX5, COMP, PIGT, FAS, USP28, TIAL1, } \\
\text { CASP2, PSMA2, MEF2D }\end{array}$ & $\begin{array}{l}\text { FAS, USP28, TIAL1, TGFB2, CDKN1A, } \\
\text { BCL11B, VSIG }\end{array}$ \\
\hline hsa-miR-371a-5p & - & $\begin{array}{l}\text { LEF1, ATP7A, } \\
\text { COL8A1 }\end{array}$ & $\begin{array}{l}\text { LEF1, SOX2, CITED2, STK4, RB1CC1, } \\
\text { BARD1, RPS6KA1, GSK3B, PSMF1, } \\
\text { MAP3K1, NR4A2, DYRK2, ITSN1, }\end{array}$ & $\begin{array}{l}\text { LEF1, SOX2, CITED2, STK4, COL8A1, } \\
\text { RNF10, MAPRE1, BTG3, CCR2, FRS2, } \\
\text { PRMT5 }\end{array}$ \\
\hline hsa-miR-4327 & RPS6KB1 & STS & $\begin{array}{l}\text { RPS6KB1, ADAMTS20, FGF10, IGF1R, } \\
\text { FGD4, RPS6KA3 }\end{array}$ & $\begin{array}{l}\text { RPS6KB1, IGF1R, FGF10, STS, PROX1, NF2, } \\
\text { IFNK }\end{array}$ \\
\hline hsa-miR-584-5p & SOD2, MORC3 & PTCH2 & $\begin{array}{l}\text { SOD2, SIX1, LRP6, FGF10, TRIM24, } \\
\text { HDAC1, CUL2, SRPK2, NBN, ETS1, DSG3, } \\
\text { MTDH, PDE3A, SLAMF7 }\end{array}$ & $\begin{array}{l}\text { SOD2, SIX1, LRP6, FGF10, TRIM24, } \\
\text { HDAC1, CUL2, SRPK2, NBN, ETS1, PRRX1, } \\
\text { FER, USP8, WWTR1 }\end{array}$ \\
\hline hsa-miR-602 & $\begin{array}{l}\text { EDN1, VDR, SOD2, } \\
\text { HTT, SLC34A2, } \\
\text { CHEK1 }\end{array}$ & APC & $\begin{array}{l}\text { EDN1, VDR, SOD2, HTT, APC, NOG, } \\
\text { ERBB4, PIM1, PPARG, ALDH1A2, CLI2, } \\
\text { SEMA3A, H1FO, DYRK2, BCL2L15, JMY, } \\
\text { PSMD2, TP53BP2, MYO18A, SHF }\end{array}$ & $\begin{array}{l}\text { NOG, ERBB4, PIM1, PPARG, CLI2, CDK13, } \\
\text { LIFR, STAT3, EDN1, VDR, SOD2, CDC27, } \\
\text { EMX2, CDK9, RTKN2, ID4, APC, ALDH1A2, } \\
\text { PPP1R8, ACSL6, ZEB1 }\end{array}$ \\
\hline hsa-miR-642b-3p & $\begin{array}{l}\text { HMGA2, PTEN, } \\
\text { CDKN1A, } \\
\text { SERPINE1, MET }\end{array}$ & $\mathrm{BCL} 11 \mathrm{~B}$ & $\begin{array}{l}\text { SERPINE1, BCL11B, PDCD10, HMGA2, } \\
\text { PTEN, RB1, CYLD, EIF2AK2, BCLAF1, } \\
\text { MAPK8, CDKN1A, WT1, CDK5R1, MTCH1, } \\
\text { EPHA7, NR4A3, CSNK2A1 }\end{array}$ & $\begin{array}{l}\text { SERPINE1, BCL11B, PDCD10, HMGA2, } \\
\text { PTEN, WT1, AMBN, CDKN1A, CDK5R1, } \\
\text { RB1, PAX6, NR2F2, PHOX2B }\end{array}$ \\
\hline hsa-miR-651 & - & - & BTC, MED1, ATG3, CHMP3 & CTC, MED1 \\
\hline hsa-miR-762 & RELA, PML & - & $\begin{array}{l}\text { RELA, PML, MAPK1, SOX7, ITCH, HIPK2, } \\
\text { BCL6, PPARD, CX3CL1, AGAP2, MYO18A, } \\
\text { PAK4, ABR, CLIP3, ADD1, PAX7, ITGB2, } \\
\text { PDE1B, MAP3K9 }\end{array}$ & $\begin{array}{l}\text { EFNB1, LIFR, MMP14, BAP1, RELA, PML, } \\
\text { MAPK1, SOX7, PAK4, ITCH, HIPK2, BCL6, } \\
\text { CX3CL1, AGAP2, PPARD, NRARP, PTCH1, } \\
\text { WARS, FTO }\end{array}$ \\
\hline hsa-miR-874 & DDC & - & $\begin{array}{l}\text { ESR1, ALDH1A2, HIPK2, PAK7, GZMB, } \\
\text { IKBKB, SORT1 }\end{array}$ & $\begin{array}{l}\text { ESR1, ALDH1A2, HIPK2, PAK7, RXRB, } \\
\text { COMT }\end{array}$ \\
\hline hsa-miR-890 & $\begin{array}{l}\text { CDK6, SERP1, F3, } \\
\text { PDCD4, ATP5G3, } \\
\text { TIMP3 }\end{array}$ & $\begin{array}{l}\text { TCF7L2, ITGA2, } \\
\text { ERRFI1 }\end{array}$ & $\begin{array}{l}\text { SORT1, UBE2B, MAX, PEG3, F3, PDCD4, } \\
\text { TCF7L2, SNAI2, AIPL1, AKAP13, ALB, TRIO, } \\
\text { REST, PROK2, KRIT, NF1, APBB1, PSME2 }\end{array}$ & $\begin{array}{l}\text { F3, CDK6, TCF7L2, SNAI2, REST, PROK2, } \\
\text { KRIT, NF1, EGF, SOX17, MARCKSL1, WARS, } \\
\text { EPS8, }\end{array}$ \\
\hline hsa-miR-939 & $\begin{array}{l}\text { TIMP1, ATM, } \\
\text { CDKN1A, NEK6, } \\
\text { SCL34A2, PRELP, } \\
\text { SLC1A2 }\end{array}$ & NGFR, COL1A1 & $\begin{array}{l}\text { TNF, BCL6, BTC, NRG1, IHH, THRA, IP6K2, } \\
\text { PAX7, CASP10, CDKN1A, CAMK1D, TRAIP, } \\
\text { WNK3, CLIP3, MT3, INHBB, TIMP1, ATM, } \\
\text { NEK6, NGFR, NACC1, USP7, CSNK2A2, } \\
\text { BCL2L2 }\end{array}$ & $\begin{array}{l}\text { BCL6, BTC, NRG1, IHH, GRN, TRAIP, } \\
\text { CDKN1A, TNF, E2F8, RXRB, RARA, DRD2, } \\
\text { CSF1, TIMP1, ATM, NGFR, MT3, NOS2, } \\
\text { AGGF1, ELN }\end{array}$ \\
\hline
\end{tabular}

pathway activation is important for HHDPC proliferation. However, our bioinformatic analysis revealed that the MAPK signaling pathway is also targeted by the upregulated miRNAs (Table 4), indicating that inhibition of MAPK signaling pathway might be involved in protective effects against ROS in HHDPCs. It has been reported that ROS activates ERK/MAPK, and ROS-mediated ERK activation induces apoptosis and senescence in several cell lines [36]. Although the molecular relationship between alopecia and MAPK signaling pathway remains to be 
Table 3 Predicted targets of miRNAs downregulated by arctiin in $\mathrm{H}_{2} \mathrm{O}_{2}$-treated $\mathrm{HHDPCs}$

\begin{tabular}{|c|c|c|c|c|}
\hline \multirow{2}{*}{ miRNA } & \multicolumn{4}{|c|}{ Target genes and functions } \\
\hline & Aging & Skin development & Apoptosis & Cell proliferation \\
\hline hsa-miR-1290 & $\begin{array}{l}\text { HMGA2, NUAK1, } \\
\text { TERF2, SLC1A2, } \\
\text { FADS1, DDC }\end{array}$ & APC, COL8A1 & $\begin{array}{l}\text { HMGA2, APC, RRN3, ITGAV, CSE1L, } \\
\text { NOTCH1, GAS, BMI1, FOXC1, ROBO1, } \\
\text { USP28 }\end{array}$ & $\begin{array}{l}\text { HMGA2, BMI1, NUAK1, APC, MLL2, RRN3, } \\
\text { ITGAV, CSE1L, NOTCH1, GAS, FOXC1, } \\
\text { ROBO1, USP28, CDC27, HES1, COL8A1, } \\
\text { NPR3, CDKN2B, FIGF, NRAS }\end{array}$ \\
\hline hsa-miR-1915-3p & $\begin{array}{l}\text { BCL2, SRF, SREBF2, } \\
\text { HSD17B10 }\end{array}$ & SRF, DDR1, EDA & $\begin{array}{l}\text { BCL2, MAPK311, ARHGEF2, CDK5R1, } \\
\text { WNT3A, MMP9, THRA, MEF2D, SET, CD44 }\end{array}$ & $\begin{array}{l}\text { DDR1, CDK2, DEAF1, TIRAP, BCL2, } \\
\text { MAP3K11, ARHGEF2, CDK5R1, WNT3A, } \\
\text { TNFSF11, WDR6, AZGP1, TAL1, DPT }\end{array}$ \\
\hline hsa-miR-2861 & P2PY2, FADS1 & NGFR, EDA & $\begin{array}{l}\text { NGFR, PTPRC, ITGA1, MAEL, FGD2, AKT2, } \\
\text { PAX8 }\end{array}$ & $\begin{array}{l}\text { NGFR, PTPRC, SLAMF1, HOXB4, AKT2, } \\
\text { HOXB4, }\end{array}$ \\
\hline hsa-miR-3665 & AQP2 & - & $\begin{array}{l}\text { AQP2, FGFR1, BOK, TRIO, NOTCH1, } \\
\text { PGAP2, PDPK1, BARD1 }\end{array}$ & $\begin{array}{l}\text { BOK, FEZF1, ABCB1, FOXO4, EIF5A2, } \\
\text { WNT9A, NDFIP1, FGFR1, NOTCH1, CDK13 }\end{array}$ \\
\hline hsa-miR-4257 & $\begin{array}{l}\text { TWIST1, CTSC, } \\
\text { HMGA1 }\end{array}$ & COL2A1 & $\begin{array}{l}\text { TWIST1, CTSC, IGF1R, IL10, GSK3B, } \\
\text { RASSF5, COL2A1, AKT1S1, CD44, ASAH2 }\end{array}$ & $\begin{array}{l}\text { TWIST1, HMGA1, IL10, INSR, MAPRE2, } \\
\text { PA2G4, PRDM1, IGF1R, MMP14, EMX2, } \\
\text { TRIM27, MCM7 }\end{array}$ \\
\hline hsa-miR-452-5p & TIMP3 & - & $\begin{array}{l}\text { SPRY2, PAX3, SOX7, LRP6, SNAI2, } \\
\text { CSNK2A2, FGD4, PKN2, ITGA6, PDCD6IP }\end{array}$ & $\begin{array}{l}\text { SPRY2, PAX3, SOX7, LRP6, SNAI2, RPA1, } \\
\text { EPS8, NFIB, MAPRE1, ODZ1, CDCA7L, } \\
\text { CD47, E2F3, PURA, RUNX1 }\end{array}$ \\
\hline hsa-miR-513a-5p & $\begin{array}{l}\text { SERP1, NEK6, } \\
\text { CDK6, DLD, } \\
\text { PRKCD, MAP2K1, } \\
\text { MORC3, LRRK2, } \\
\text { SLC1A2 }\end{array}$ & $\begin{array}{l}\text { WNT7A, SFN, T } \\
\text { FAP2B, APC }\end{array}$ & $\begin{array}{l}\text { SPRY2, MLL, GATA3, BCL6, PRKCD, NEK6, } \\
\text { MED1, PLK2, WNT7A, SFN, APC, HOXA5, } \\
\text { AKAP13, USP47, MAP2K4, ISL1, MITF, } \\
\text { STAT1, XIAP, TFAP2B, HDAC2, TRIM2, } \\
\text { CREB1, MAP3K7, WNK3, SOS1, FGD4 }\end{array}$ & $\begin{array}{l}\text { TFAP2B, WNT7A, APC, HGF, EBXW7, TSC1, } \\
\text { KRAS, RXRB, XIAP, SPRY2, GATA3, BCL6, } \\
\text { HOXA5, ISL1, MITF, STAT1, NFIB, E2F7, } \\
\text { MAGI2, PDKK, HDAC2, MED1, EHF, LIFR, } \\
\text { PURA, GATA2, ATF3, VIP, SOX11, RUNX1, } \\
\text { RNF139, PCM1, TSHR, EPS8 }\end{array}$ \\
\hline hsa-miR-572 & - & - & - & - \\
\hline hsa-miR-629-3p & $\begin{array}{l}\text { SOD2, VDR, EDN1, } \\
\text { CHEK1, SLC34A2 }\end{array}$ & - & $\begin{array}{l}\text { THOC1, MYO18A, TP53BP2, SOD2, VDR, } \\
\text { EDN1, APC, PPARG, PIM1, ERBB4, PSMD2, } \\
\text { PERP, BCL2L15 }\end{array}$ & $\begin{array}{l}\text { DLG3, RTKN2, CDK9, STAT3, SOD2, VDR, } \\
\text { EDN1, PPARG, PIM1, ERBB4, APC, STAT6, } \\
\text { PDGFC, ZEB1, ID4, LIFR, NOLC1, EPHB1, } \\
\text { ACSL6, EREG, CDK13, CDC27 }\end{array}$ \\
\hline hsa-miR-765 & $\begin{array}{l}\text { VDR, RELA, SOCS3, } \\
\text { TIMP3, LOXL2 }\end{array}$ & PDGFA, ERRFI1 & $\begin{array}{l}\text { DLG5, RARG, MED1, EGLN2, VDR, RELA, } \\
\text { SOCS3, ERBB4, RNF41, ATG7, ARHGEF11, } \\
\text { PDE5A, CXCL12, GLI3, DIDO1, CASP9, } \\
\text { ACIN1 }\end{array}$ & $\begin{array}{l}\text { CXCL12, GL13, DLG5, RARG, VDR, RELA, } \\
\text { ERBB4, PDE5A, MED1, PDGFA, CD34, } \\
\text { GPC3, PDX1, COL8A1, PES1, TSC2, SF1, } \\
\text { FTO, GABBR1, }\end{array}$ \\
\hline hsa-miR-875-5p & TGFB3, SMC5 & TCF7L2 & $\begin{array}{l}\text { TGFB3, TCF7L2, EYA1, MDM4, MEF2C, } \\
\text { EGFR, WNK3 }\end{array}$ & $\begin{array}{l}\text { MDM4, MEF2C, EGFR, FRS2, TGFB3, EYA1, } \\
\text { TOB2, TBX18, CEP120, TCF7L2, TIRAP, } \\
\text { RNF139, SALL1 }\end{array}$ \\
\hline hsa-miR-940 & - & - & - & - \\
\hline
\end{tabular}

investigated, our results indicate the possibility that regulating MAPK signaling might be important for treating or preventing alopecia.

Our bioinformatic analysis also revealed that WNT signaling pathway is putatively targeted by the miRNAs altered following arctiin treatment. Wnt signaling has also been implicated in alopecia. A recent study demonstrated that Wnt10A, which is a member of the Wnt family, is involved in the etiology of androgenetic alopecia [37]. A Wnt10A deficiency causes deregulation of the hair cycle by shortening the anagen phase, which is observed in androgenetic alopecia hair follicles [37]. Funato et al. demonstrated that $\mathrm{H}_{2} \mathrm{O}_{2}$-induced ROS can regulate $\mathrm{Wnt} / \beta$-catenin signaling pathways [38]. Also, it was recently reported that the minoxidil-mediated anagen prolongation effect is due to $\beta$-catenin pathway activation [39]. Although further investigations are necessary to clarify the molecular interplay between ROS and Wnt signaling pathway in hair follicles and in patients with alopecia, our results suggest that arctiin-mediated antioxidative effects in HHDPCs may be involved in regulating Wnt signaling.

\section{Conclusions}

In summary, our results demonstrate that arctiin regulates $\mathrm{H}_{2} \mathrm{O}_{2}$-induced cell death, cell cycle arrest, and ROS production in HHDPCs. Arctiin also inhibits $\mathrm{H}_{2} \mathrm{O}_{2}$-induced cell senescence. We identified 30 miRNAs that were significantly expressed following arctiin treatment, indicating that they may be involved in arctiin-mediated antioxidative processes. Taken together, our results provide evidence that the novel putative chemoreagent arctiin can prevent HHDP cell damage mediated by oxidative stress. 
Table 4 Main functions of upregulated miRNAs predicted by bioinformatic analysis

\begin{tabular}{|c|c|c|c|c|c|}
\hline $\begin{array}{l}\text { miRNA } \\
\text { (Homo sapiens) }\end{array}$ & $\begin{array}{c}\text { Putative } \\
\text { target genes }\end{array}$ & KEGG pathway & $\begin{array}{l}\text { Genes involved } \\
\text { in the term }\end{array}$ & $\begin{array}{c}\% \text { of involved } \\
\text { genes/total genes }\end{array}$ & $p$-value \\
\hline miR-1181 & 2 & - & - & - & - \\
\hline \multirow[t]{2}{*}{ miR-125a-5p } & 162 & Pathways in cancer & 8 & 4.9 & 3.60E-02 \\
\hline & & Cell cycle & 4 & 2.5 & 1.20E-01 \\
\hline \multirow[t]{3}{*}{ miR-21-3p } & 210 & Cell adhesion molecules & 7 & 3.3 & 4.70E-03 \\
\hline & & Ubiquitin mediated proteolysis & 6 & 2.9 & 2.30E-02 \\
\hline & & Oocyte meiosis & 5 & 2.4 & 4.20E-02 \\
\hline \multirow[t]{4}{*}{ miR-29b-1-5p } & 265 & Insulin signaling pathway & 5 & 1.9 & 8.50E-02 \\
\hline & & Cell cycle & 4 & 1.5 & 2.00E-01 \\
\hline & & Wnt signaling pathway & 4 & 1.5 & 2.90E-01 \\
\hline & & Jak-STAT signaling pathway & 4 & 1.5 & 3.00E-01 \\
\hline \multirow[t]{4}{*}{ miR-3663-3p } & 305 & MAPK signaling pathway & 12 & 3.9 & 5.90E-03 \\
\hline & & Pathways in cancer & 11 & 3.6 & 5.50E-02 \\
\hline & & Focal adhesion & 7 & 2.3 & 1.30E-01 \\
\hline & & Cytokine-cytokine receptor interaction & 7 & 2.3 & 3.00E-01 \\
\hline \multirow[t]{2}{*}{ miR-371a-5p } & 351 & Spliceosome & 8 & 2.3 & 4.20E-03 \\
\hline & & Wnt signaling pathway & 7 & 2 & 3.60E-02 \\
\hline \multirow[t]{4}{*}{ miR-4327 } & 112 & MAPK signaling pathway & 4 & 3.6 & $1.20 \mathrm{E}-01$ \\
\hline & & Pathways in cancer & 4 & 3.6 & 1.80E-01 \\
\hline & & Melanoma & 3 & 2.7 & 4.00E-02 \\
\hline & & Calcium signaling pathway & 3 & 2.7 & 1.90E-01 \\
\hline \multirow[t]{2}{*}{ miR-584-5p } & 288 & MAPK signaling pathway & 8 & 2.8 & $9.70 \mathrm{E}-02$ \\
\hline & & Pathways in cancer & 8 & 2.8 & 2.10E-01 \\
\hline \multirow[t]{4}{*}{ miR-602 } & 302 & MAPK signaling pathway & 7 & 2.3 & 2.20E-01 \\
\hline & & Insulin signaling pathway & 6 & 2 & 5.30E-02 \\
\hline & & Alzheimer's disease & 6 & 2 & 1.00E-01 \\
\hline & & Calcium signaling pathway & 6 & 2 & 1.30E-01 \\
\hline miR-629-3p & 445 & Pathways in cancer & 10 & 2.3 & 2.10E-01 \\
\hline \multirow[t]{3}{*}{ miR-642b-3p } & 262 & Glioma & 4 & 1.5 & 3.20E-02 \\
\hline & & Melanoma & 4 & 1.5 & 4.30E-02 \\
\hline & & Cell adhesion molecules & 5 & 1.8 & 5.70E-02 \\
\hline \multirow[t]{3}{*}{ miR-651 } & 60 & Calcium signaling pathway & 3 & 4.3 & 5.40E-01 \\
\hline & & Ubiquitin mediated proteolysis & 3 & 4.3 & $6.00 \mathrm{E}-02$ \\
\hline & & Regulation of autophagy & 2 & 2.9 & $9.90 \mathrm{E}-02$ \\
\hline \multirow[t]{3}{*}{ miR-762 } & 534 & Axon guidance & 16 & 3 & $6.60 \mathrm{E}-07$ \\
\hline & & MAPK signaling pathway & 16 & 3 & 2.90E-03 \\
\hline & & Wnt signaling pathway & 13 & 2.4 & 4.00E-04 \\
\hline \multirow[t]{2}{*}{ miR-874 } & 176 & B and T cell receptor signaling pathway & 4 & 2.3 & 2.20E-02 \\
\hline & & MAPK signaling pathway & 4 & 2.3 & 3.70E-01 \\
\hline \multirow[t]{2}{*}{ mir-890 } & 325 & Wnt signaling pathway & 7 & 2.1 & $6.50 \mathrm{E}-02$ \\
\hline & & ErbB signaling pathway & 5 & 1.5 & 8.10E-02 \\
\hline
\end{tabular}


Table 4 Main functions of upregulated miRNAs predicted by bioinformatic analysis (Continued)

\begin{tabular}{lllrr}
\hline miR-939 365 & Calcium signaling pathway & 10 & 2.4 & $1.30 \mathrm{E}-02$ \\
& ErbB signaling pathway & 5 & 1.2 & $1.20 \mathrm{E}-01$ \\
& p53 signaling pathway & 4 & 0.9 & $1.80 \mathrm{E}-01$ \\
& Wht signaling pathway & 6 & 1.4 & $2.20 \mathrm{E}-01$ \\
\hline
\end{tabular}

\section{Methods}

\section{Cell culture and reagents}

HHDPCs provided by Innoprot (Bizkaia, Spain) were purchased and maintained in Dulbecco's modified Eagle's medium (DMEM) containing 10\% fetal bovine serum (HyClone; Thermo Fisher Scientific Inc., Waltham, MA, USA) and 1\% penicillin-streptomycin (Gibco; Life Technologies, Grand Island, NY, USA) at $37^{\circ} \mathrm{C}$ and $5 \% \mathrm{CO}_{2}$. Arctiin, propidium iodide (PI) for cell cycle analysis and 2' $7^{\prime}$-dichlorofluorescein diacetate (DCF-DA) for intracellular ROS analysis were purchased from Sigma-Aldrich (St. Louis, MO, USA).
Water-soluble tetrazolium salt (WST-1) assay

To analyze cell viability, HHDPCs were plated on 96well culture dishes. After overnight growth, the cells were treated with various concentrations of arctiin $(0-60 \mu \mathrm{M})$ for $24 \mathrm{~h}$. WST-1 assay solution (EZ-Cytox Cell Viability Assay Kit, Itsbio, Seoul, Korea) was added for $40 \mathrm{~min}$ after the 24-h incubation. Cell viability was measured using an iMark microplate reader (Bio-Rad, Hercules, CA, USA) at $490 \mathrm{~nm}$ with a reference filter of $620 \mathrm{~nm}$. The results are presented as mean percentage \pm standard deviation (S.D.) of three independent experiments.

Table 5 Main functions of downregulated miRNAs predicted by bioinformatic analysis

\begin{tabular}{|c|c|c|c|c|c|}
\hline $\begin{array}{l}\text { miRNA } \\
\text { (Homo sapiens) }\end{array}$ & $\begin{array}{l}\text { Putative } \\
\text { target genes }\end{array}$ & KEGG pathway & $\begin{array}{l}\text { Genes involved } \\
\text { in the term }\end{array}$ & $\begin{array}{c}\% \text { of involved } \\
\text { genes/total genes }\end{array}$ & $p$-value \\
\hline \multirow[t]{5}{*}{ miR-1290 } & 593 & Pathways in cancer & 17 & 2.9 & 4.00E-02 \\
\hline & & Focal adhesion & 14 & 2.4 & 7.90E-03 \\
\hline & & Insulin signaling pathway & 13 & 2.2 & 7.60E-04 \\
\hline & & MAPK signaling pathway & 12 & 2 & $1.90 \mathrm{E}-01$ \\
\hline & & ErbB signaling pathway & 11 & 1.9 & 2.80E-04 \\
\hline \multirow[t]{2}{*}{ miR-1915-3p } & 351 & Wnt signaling pathway & 8 & 2.3 & 5.60E-03 \\
\hline & & Pathways in cancer & 7 & 2 & 3.30E-01 \\
\hline \multirow[t]{3}{*}{ miR-2861 } & 170 & Fc gamma R-mediated phagocytosis & 4 & 2.2 & 3.60E-02 \\
\hline & & MAPK signaling pathway & 6 & 3.4 & $5.10 \mathrm{E}-02$ \\
\hline & & Arachidonic acid metabolism & 3 & 1.7 & $6.80 \mathrm{E}-02$ \\
\hline \multirow[t]{3}{*}{ miR-3665 } & 195 & Neurotrophin signaling pathway & 4 & 2.1 & 1.10E-01 \\
\hline & & Insulin signaling pathway & 4 & 2.1 & 1.30E-01 \\
\hline & & MAPK signaling pathway & 4 & 2.1 & 4.70E-01 \\
\hline miR-4257 & 197 & - & - & - & - \\
\hline \multirow[t]{3}{*}{ miR-452-5p } & 327 & Oocyte meiosis & 8 & 2.3 & $1.30 \mathrm{E}-03$ \\
\hline & & Wnt signaling pathway & 7 & 2 & 2.60E-02 \\
\hline & & ECM-receptor interaction & 5 & 1.4 & $3.80 \mathrm{E}-02$ \\
\hline \multirow[t]{3}{*}{ miR-513a-5p } & 980 & MAPK signaling pathway & 25 & 2.6 & 1.00E-02 \\
\hline & & Pathways in cancer & 24 & 2.4 & 1.30E-01 \\
\hline & & Regulation of actin cytoskeleton & 20 & 2 & $2.50 \mathrm{E}-02$ \\
\hline miR-572 & 6 & - & - & - & - \\
\hline miR-629-3p & 445 & Pathways in cancer & 10 & 2.3 & 2.10E-01 \\
\hline miR-765 & 548 & Cytokine-cytokine receptor interaction & 11 & 2 & 2.00E-01 \\
\hline \multirow[t]{2}{*}{ miR-875-5p } & 181 & MAPK signaling pathway & 6 & 3.3 & 7.30E-02 \\
\hline & & Spliceosome & 5 & 2.8 & 2.10E-02 \\
\hline miR-940 & - & - & - & - & - \\
\hline
\end{tabular}




\section{PI-based cell cycle analysis}

To analyze cells in different phases of the cell cycle, treated HHDPCs $\left(4 \times 10^{3}\right)$ were gathered by trypsinization and fixed by adding cold $70 \%$ ethanol at $-20^{\circ} \mathrm{C}$ for $1 \mathrm{~h}$. After fixation, cells were stained by incubating with PI staining solution $(50 \mu \mathrm{g} / \mathrm{ml} \mathrm{PI}, 0.5 \%$ Triton X-100, and $100 \mu \mathrm{g} / \mathrm{ml} \mathrm{RNase)}$ at $37^{\circ} \mathrm{C}$ for $1 \mathrm{~h}$. The distribution of each cell cycle phase was determined by evaluating the intensity of fluorescence PI staining using the FL2-H channel of a FACSCalibur (BD Biosciences, Franklin Lakes, NJ, USA).

\section{DCF-DA-based ROS analysis}

To analyze intracellular ROS levels in HHDPCs, treated cells were washed, trypsinized, and collected. Cells were diluted in $20 \mu \mathrm{M}$ DCF-DA/phosphate-buffered saline (PBS) and incubated at room temperature for $1 \mathrm{~h}$ in the dark. After incubation, cells were washed once with PBS and subjected to flow cytometer-based fluorescence analysis using a BD FACSCalibur flow cytometer (BD Biosciences).

$\beta$-galactosidase ( $\beta$-Gal)-based cellular senescence analysis To analyze the level of cellular senescence in HHDPCs after arctiin and $\mathrm{H}_{2} \mathrm{O}_{2}$ treatment, treated cells were gathered and fixed by the addition of $2 \%$ formaldehyde $/ 0.2 \%$ glutaraldehyde. After fixation, senescence-associated $\beta$-galactosidase (SA- $\beta$-Gal) staining solution (Biovision, Milpitas, CA, USA) was added to the fixed cells and incubated at $37^{\circ} \mathrm{C}$ overnight. Senescent cells (positive blue color) were observed and counted using a bright-field microscope at $\times 200$ magnification, and the percentages were determined.

\section{Microarray-based miRNA expression analysis}

To investigate which miRNAs are altered in our study, treated HHDPCs were gathered and lysed using TRIzol reagent (Life Technologies) for total RNA purification. Total RNA was extracted from the lysed cells according to the manufacturer's protocol and estimated its integrity and purity was estimated using an Agilent 2100 Bioanalyzer (Agilent Technologies, Santa Clara, CA, USA) and a MaestroNano ${ }^{\circ}$ microvolume spectrophotometer (Maestrogen, Las Vegas, NV, USA). We confirmed that the RNA samples had values integrity values higher than 8.0 and A260/280 and A260/230 values greater than 1.8. The qualified RNA samples were subjected to miRNA microarray analysis as described previously [40]. Briefly, RNAs were dephosphorylated and labeled with cyanine 3-pCp (Agilent Technologies). The labeled samples were dried and treated with GE Blocking Agent (Agilent Technologies) to reduce background or nonspecific binding to the probe onto the microarray. Then, the samples were hybridized to the SurePrint G3 Human v16 miRNA 8x60K microarray (Agilent Technologies) in the Agilent Microarray Hybridization Chamber (Agilent Technologies) for $20 \mathrm{~h}$. After hybridization, the array was scanned using an Agilent SureScan Microarray Scanner (Agilent Technologies) and quantitated using Agilent Feature Extraction Software (version 10.7, Agilent Technologies). Derived data were analyzed using GeneSpring GX software, version 11.5 (Agilent Technologies). The data were filtered using flagpresent and $t$-tests to identify miRNAs for further analysis. miRNA expression was evaluated by assessing the fluorescence ratio between two samples. Those displaying >2.0fold increases or decreases were selected for further bioinformatic analysis.

\section{Bioinformatical tool-based biological analysis of miRNAs}

To investigate the biological meaning of miRNAs with significantly altered expression, we used three kinds of bioinformatical tools: MicroCosm Targets Version 5 (http:// www.ebi.ac.uk/enright-srv/microcosm/htdocs/targets/v5/), AmiGo 2 GO analysis tool and DAVID (Database for Annotation, Visualization and Interrogate Discovery, http:// david.abcc.ncifcrf.gov/home.jsp) bioinformatics resources v6.7 [41]. Using the first tool, we predicted the putative target genes of the altered miRNAs, and the second tool was used to group target genes into four categories: aging, skin development, apoptosis, and cell proliferation. Finally, the targets were analyzed using the Kyoto Encyclopedia of Genes and Genomes (KEGG) pathway-based enrichment analysis program in the bioinformatic database DAVID. The Ensembl transcript ID lists of target genes were gathered and subjected to pathway analysis using the KEGG program in DAVID bioinformatic resources. The Ease score, which is a modified Fisher's extract P-value, was fixed at 0.5 and meaningful KEGG pathways showing a value of $>0.9 \%$ (percentage of involved target genes/total target genes) were selected.

\section{Competing interests}

The authors declare that they have no competing interests.

\section{Authors' contributions}

SB, KML perform the experiments and Figures. JPL, KSL, GTL: Bioinformatic analysis and experimental design. HJC, ISA, KKL, HJJ, KJA: Experimental design and advising. SB and SA: Experimental design and write the manuscript. All authors read and approved the final manuscript.

\section{Acknowledgements}

This study was supported by a grant of the Korean Health Technology R\&D Project (Grant No. HN13C0075), Ministry of Health \& Welfare, Republic of Korea. Dr. Seunghee Bae was supported by the KU Research Professor Program of Konkuk University.

\section{Author details}

${ }^{1}$ Korea Institute for Skin and Clinical Sciences, Konkuk University, 120 Neungdong-ro, Gwangjin-gu, Seoul 143-701, Republic of Korea. ${ }^{2}$ Coreana Cosmetics Co., Ltd, Cheonan-si, Chungcheongnam-do 330-833, Republic of Korea. ${ }^{3}$ Department of Dermatology, Konkuk University School of Medicine, 120 Neungdong-ro, Gwangjin-gu, Seoul 143-701, Republic of Korea. 
Received: 2 August 2014 Accepted: 24 September 2014

Published: 30 September 2014

\section{References}

1. Ray PD, Huang BW, Tsuji Y: Reactive oxygen species (ROS) homeostasis and redox regulation in cellular signaling. Cell Signal 2012, 24:981-990.

2. Birben E, Sahiner UM, Sackesen C, Erzurum S, Kalayci O: Oxidative stress and antioxidant defense. World Allergy Organ J 2012, 5:9-19.

3. Agarwal ML, Taylor WR, Chernov MV, Chernova OB, Stark GR: The p53 network. J Biol Chem 1998, 273:1-4

4. Son Y, Cheong YK, Kim NH, Chung HT, Kang DG, Pae HO: Mitogenactivated protein kinases and reactive oxygen species: how can ROS activate MAPK pathways? J Signal Transduct 2011, 2011:792639.

5. Pillai S, Oresajo C, Hayward J: Ultraviolet radiation and skin aging: roles of reactive oxygen species, inflammation and protease activation, and strategies for prevention of inflammation-induced matrix degradation a review. Int J Cosmet Sci 2005, 27:17-34.

6. Bickers DR, Athar M: Oxidative stress in the pathogenesis of skin disease. J Invest Dermatol 2006, 126:2565-2575.

7. Bahta AW, Farjo N, Farjo B, Philpott MP: Premature senescence of balding dermal papilla cells in vitro is associated with p16(INK4a) expression. J Invest Dermatol 2008, 128:1088-1094.

8. Naito A, Midorikawa T, Yoshino T, Ohdera M: Lipid peroxides induce early onset of catagen phase in murine hair cycles. Int J Mol Med 2008, 22:725-729.

9. Trueb RM: Oxidative stress in ageing of hair. Int J Trichology 2009, 1:6-14.

10. McElwee KJ, Gilhar A, Tobin DJ, Ramot Y, Sundberg JP, Nakamura M Bertolini M, Inui S, Tokura Y, King LE, Duque-Estrada B, Tosti A, Keren A, Itami S, Shoenfeld Y, Zlotogorski A, Paus R: What causes alopecia areata?: section editors: Ralf Paus, Manchester/Lubeck and Raymond Cho, San Francisco. Exp Dermatol 2013, 22:609-626.

11. Driskell RR, Clavel C, Rendl M, Watt FM: Hair follicle dermal papilla cells at a glance. J Cell Sci 2011, 124:1179-1182

12. Bichsel KJ, Gogia N, Malouff T, Pena Z, Forney E, Hammiller B, Watson P, Hansen LA: Role for the epidermal growth factor receptor in chemotherapy-induced alopecia. PLoS One 2013, 8:e69368.

13. Chen PH, Wang CY, Hsia CW, Ho MY, Chen A, Tseng MJ, Wu YF, Chen HM, Huang TH, Liu HT, Shui HA: Impact of taxol on dermal papilla cells-a proteomics and bioinformatics analysis. J Proteomics 2011, 74:2760-2773.

14. Prieto VG, Sadick NS, Shea CR: Androgenetic alopecia: analysis of proliferation and apoptosis. Arch Dermatol 2002, 138:1101-1102.

15. Bakry OA, Elshazly RM, Shoeib MA, Gooda A: Oxidative stress in alopecia areata: a case-control study. Am J Clin Dermatol 2014, 15:57-64.

16. Shin H, Yoo HG, Inui S, Itami S, Kim IG, Cho AR, Lee DH, Park WS, Kwon O, Cho $\mathrm{KH}$, Won $\mathrm{CH}$ : Induction of transforming growth factor-beta 1 by androgen is mediated by reactive oxygen species in hair follicle dermal papilla cells. BMB Rep 2013, 46:460-464

17. Luanpitpong S, Nimmannit U, Chanvorachote P, Leonard SS, Pongrakhananon V, Wang LY, Rojanasakul Y: Hydroxyl radical mediates cisplatin-induced apoptosis in human hair follicle dermal papilla cells and keratinocytes through Bcl-2-dependent mechanism. Apoptosis 2011 16:769-782.

18. Hirose M, Yamaguchi T, Lin C, Kimoto N, Futakuchi M, Kono T, Nishibe S, Shirai T: Effects of arctiin on PhIP-induced mammary, colon and pancreatic carcinogenesis in female Sprague-Dawley rats and MelQx-induced hepatocarcinogenesis in male F344 rats. Cancer Lett 2000, 155:79-88.

19. Lee S, Shin S, Kim H, Han S, Kim K, Kwon J, Kwak JH, Lee CK, Ha NJ, Yim D: Anti-inflammatory function of arctiin by inhibiting COX-2 expression via NF-kappaB pathways. J Inflamm (Lond) 2011, 8:16.

20. Hayashi K, Narutaki K, Nagaoka Y, Hayashi T, Uesato S: Therapeutic effect of arctiin and arctigenin in immunocompetent and immunocompromised mice infected with influenza A virus. Biol Pharm Bull 2010, 33:1199-1205.

21. Matsuzaki Y, Koyama M, Hitomi T, Yokota T, Kawanaka M, Nishikawa A, Germain D, Sakai T: Arctiin induces cell growth inhibition through the down-regulation of cyclin D1 expression. Oncol Rep 2008, 19:721-727.

22. Cha HJ, Lee GT, Lee KS, Lee KK, Hong JT, Lee NK, Kim SY, Lee BM, An IS, Hahn HJ, Ahn KJ, Lee SJ, An S, Bae S: Photoprotective effect of arctiin against ultraviolet $\mathrm{B}$-induced damage in $\mathrm{HaCaT}$ keratinocytes is mediated by microRNA expression changes. Mol Med Rep 2014, 10:1363-1370
23. Lee GT, Cha HJ, Lee KS, Lee KK, Hong JT, Ahn KJ, An IS, An S, Bae S: Arctiin induces an UVB protective effect in human dermal fibroblast cells through microRNA expression changes. Int J Mol Med 2014, 33:640-648.

24. Mao Z, Ke Z, Gorbunova V, Seluanov A: Replicatively senescent cells are arrested in G1 and G2 phases. Aging 2012, 4:431-435.

25. Colavitti R, Finkel T: Reactive oxygen species as mediators of cellular senescence. IUBMB Life 2005, 57:277-281.

26. Ambros $V$, Lee RC: Identification of microRNAs and other tiny noncoding RNAs by cDNA cloning. Methods Mol Biol 2004, 265:131-158.

27. Pillai RS, Bhattacharyya SN, Filipowicz W: Repression of protein synthesis by miRNAs: how many mechanisms? Trends Cell Biol 2007, 17:118-126.

28. Cheng AM, Byrom MW, Shelton J, Ford LP: Antisense inhibition of human miRNAs and indications for an involvement of miRNA in cell growth and apoptosis. Nucleic Acids Res 2005, 33:1290-1297.

29. Chen JF, Mandel EM, Thomson JM, Wu Q, Callis TE, Hammond SM, Conlon FL, Wang DZ: The role of microRNA-1 and microRNA-133 in skeletal muscle proliferation and differentiation. Nat Genet 2006, 38:228-233.

30. An IS, An S, Kang SM, Choe TB, Lee SN, Jang HH, Bae S: Titrated extract of Centella asiatica provides a UVB protective effect by altering microRNA expression profiles in human dermal fibroblasts. Int J Mol Med 2012, 30:1194-1202

31. Goodarzi HR, Abbasi A, Saffari M, Fazelzadeh Haghighi M, Tabei MB, Noori Daloii MR: Differential expression analysis of balding and nonbalding dermal papilla microRNAs in male pattern baldness with a microRNA amplification profiling method. Br J Dermatol 2012, 166:1010-1016.

32. Bae S, Lee EJ, Lee JH, Park IC, Lee SJ, Hahn HJ, Ahn KJ, An S, An IS, Cha HJ: Oridonin protects $\mathrm{HaCaT}$ keratinocytes against hydrogen peroxideinduced oxidative stress by altering microRNA expression. Int J Mol Med 2014, 33:185-193.

33. Sayama K, Kajiya K, Sugawara K, Sato S, Hirakawa S, Shirakata Y, Hanakawa Y, Dai XJ, Ishimatsu-Tsuji Y, Metzger D: Inflammatory mediator TAK1 regulates hair follicle morphogenesis and anagen induction shown by using keratinocyte-specific TAK1-deficient mice. PLoS One 2010, 5:e11275.

34. Omori E, Morioka S, Matsumoto K, Ninomiya-Tsuji J: TAK1 regulates reactive oxygen species and cell death in keratinocytes, which is essential for skin integrity. J Biol Chem 2008, 283:26161-26168.

35. Han JH, Kwon OS, Chung JH, Cho KH, Eun HC, Kim KH: Effect of minoxidil on proliferation and apoptosis in dermal papilla cells of human hair follicle. J Dermatol Sci 2004, 34:91-98.

36. Cagnol S, Chambard JC: ERK and cell death: mechanisms of ERK-induced cell death-apoptosis, autophagy and senescence. FEBS J 2010, 277:2-21.

37. Heilmann S, Kiefer AK, Fricker N, Drichel D, Hillmer AM, Herold C, Tung JY, Eriksson N, Redler S, Betz RC, Li R, Karason A, Nyholt DR, Song K, Vermeulen SH, Kanoni S, Dedoussis G, Martin NG, Kiemeney LA, Mooser V, Stefansson K, Richards JB, Becker T, Brockschmidt FF, Hinds DA, Nothen MM: Androgenetic alopecia: identification of four genetic risk loci and evidence for the contribution of WNT signaling to its etiology. J Invest Dermatol 2013, 133:1489-1496.

38. Funato $Y$, Michiue $T$, Asashima M, Miki H: The thioredoxin-related redox-regulating protein nucleoredoxin inhibits Wnt-beta-catenin signalling through dishevelled. Nat Cell Biol 2006, 8:501-U135.

39. Kwack MH, Kang BM, Kim MK, Kim JC, Sung YK: Minoxidil activates betacatenin pathway in human dermal papilla cells: a possible explanation for its anagen prolongation effect. J Dermatol Sci 2011, 62:154-159.

40. Lee EJ, Cha HJ, Ahn KJ, An IS, An S, Bae S: Oridonin exerts protective effects against hydrogen peroxideinduced damage by altering microRNA expression profiles in human dermal fibroblasts. Int J Mol Med 2013, 32:1345-1354

41. da Huang W, Sherman BT, Tan Q, Collins JR, Alvord WG, Roayaei J, Stephens R, Baseler MW, Lane HC, Lempicki RA: The DAVID gene functional classification tool: a novel biological module-centric algorithm to functionally analyze large gene lists. Genome Biol 2007, 8:R183.

\section{doi:10.1186/0717-6287-47-50}

Cite this article as: Bae et al:: Arctiin blocks hydrogen peroxide-induced senescence and cell death though microRNA expression changes in human dermal papilla cells. Biological Research 2014 47:50. 